\title{
Alvimopan, REMS and E.A.S.E! How Are They Related?
}

\author{
Abhijit S. Nair ${ }^{1 *}$ \\ ${ }^{1}$ Department of Anaesthesiology, Basavatarakam Indo-American \\ Cancer Hospital and Research Institute, Road No.10, Banjara Hills, \\ Hyderabad-500034, Telangana State, India.
}

*Corresponding to: Abhijit S. Nair, Email: abhijitnair95@gmail.com.

Alvimopan is a US-FDA approved drug used orally in patients who undergo intestinal surgeries. Pharmacologically alvimopan is an orally available, peripherally acting $\mu$-opioid receptor antagonist (PAM-OR). The drug is used as a prophylaxis to prevent peri-operative opioid induced ileus. Unlike naloxone, it does not cross blood-brain barrier. This ensures reversal of the peripherally present $\mu$-opioid receptor in the gut without affecting the centrally mediated analgesia. It is available as oral capsules of $12 \mathrm{mg}$. The recommended dose is $12 \mathrm{mg}$ twice daily for 7 days, total 15 doses only with the first dose before starting the surgery ${ }^{[1]}$. $\mu$-opioid receptors are present on the immune cells in the lamina propria, myenteric and submucosal neurons of human gastrointestinal tract ${ }^{[2]}$. The gut $\mu$ receptors gets affected with the systemically administered opioids in the perioperative period which contributes to ileus and constipation leading to significant perioperative morbidity.

Before 2007, alvimopan was used at a dose of 0.5-1 mg twice daily in patients with opioid induced constipation (OIC) who were using long term opioids for the management of chronic pain. However, the long term use was responsible for adverse cardiovascular events (myocardial infarction) in many patients ${ }^{[3]}$. This lead to the discontinuation of alvimopan in the above mentioned setting. Later in 2008, the drug resurfaced for clinical use with a different dose and a different indication. This time US-FDA approved the use of alvimopan for preventing opioid induced gut hypomotility in patients undergoing gastrointestinal surgeries involving resection and anastomosis, for 15 doses only and starting preoperatively. The first dose of $12 \mathrm{mg}$ in the form of capsule is administered prior to surgery. After that, it is continued for 7 days at a dosing of $12 \mathrm{mg}$ twice daily i.e. a total of 15 doses. The long term use in chronic pain patients having OIC is no longer advocated.

http://mo.qingres.com

\section{GOPEN ACCESS}

DOI: $10.20900 / \mathrm{mo} .20170021$

Received: July 12, 2017

Accepted: September 14, 2017

Published: October 25, 2017

Copyright: (2017 Cain et al. This is an open access article distributed under the terms of the Creative Commons Attribution License, which permits unrestricted use, distribution, and reproduction in any medium, provided the original author and source are credited.

However, the resurgence of alvimopan came with lot of terms and conditions. The previous long term use of alvimopan was associated with life threatening events. This time, US-FDA involved manufacturers in the REMS (Risk Evaluation and Mitigation Strategy) program ${ }^{[4]}$. The manufacturers of drugs responsible for serious life threatening events earlier were supposed to ensure that benefits of a particular drug or biological product clearly outweighs its risks. With the REMS strategy, the dose of alvimopan changed along with the duration of use. Alvimopan is not easily available. It can be procured by those hospitals that perform intestinal surgeries. The pharmacy of those hospitals needs to be enrolled in the EASE ENTEREG REMS PROGRAM. Entereg is the brand name of alvimopan with which it is 
sold by Merck pharmaceuticals. EASE stands for ENTEREG Access Support and Education. The EASE program is implemented to streamline the use of alvimopan by registered pharmacies and hospitals only. The program does not allow more than 15 doses of alvimopan to get dispensed. The drug is issued only to hospitalised patients and is not at all used in outpatients. Fifty doses are meant for a single patient. The capsules are not transferrable to other patients ${ }^{[5]}$. A strict checklist is followed before enrolling a patient for the use of alvimopan. Patients with severe hepatic impairment, end-stage renal disease, complete gastrointestinal obstruction, pancreatic/gastric anastomosis, previous surgery for bowel obstruction (laparotomy with resection) are not prescribed alvimopan. Similarly, patients who were prescribed systemic opioids for more than 7 days prior to the scheduled surgery are not candidates who should be taking alvimopan. The cost of 15 approved doses of alvimopan comes to approximately $\$ 950$. Therefore, the patients should be selected properly after going through the checklist.

\section{CONFLICTS OF INTEREST}

The author claims no conflicts of interest.

\section{REFERENCES}

1. Nair A. Alvimopan for post-operative ileus: What we should know? Acta Anaesthesiol Taiwan. 2016; 54(3): 97-98.

2. Holzer P. Opioid receptors in the gastrointestinal tract. Regulatory peptides. 2009; 155(1-3): 1117.

3. Curran MP, Robins G, W, Scott LJ, Perry CM. Alvimopan. Drugs. 2008; 68(14): 2011-2019.

4. Balian JD, Wherry JC, Malhotra R, Perentesis $\mathrm{V}$. Roadmap to risk evaluation and mitigation strategies (REMS) success. Ther Adv Drug Saf. 2010; 1(1): 21-38

5. Bream-Rouwenhorst HR, Cantrell MA. Alvimopan for postoperative ileus. Am J Health Syst Pharm. 2009; 66(14): 1267-1277. 